\title{
Expansão urbana do município de São Miguel do Oeste/SC, num contexto geomorfológico
}

\author{
Urban expansion of the municipality of São Miguel do Oeste/SC, in a geomorphological context \\ Expansión urbana del municipio de São Miguel do Oeste / SC, en un contexto geomorfológico
}

Recebido: 16/10/2021 | Revisado: 24/10/2021 | Aceito: 01/11/2021 | Publicado: 02/11/2021

Celí Maziero

ORCID: https://orcid.org/0000-0002-7071-2762

Universidade do Oeste de Santa Catarina, Brasil E-mail: celimaziero1@ hotmail.com

José Ricardo da Rocha Campos

ORCID: https://orcid.org/0000-0002-5162-3158

Universidade Tecnológica Federal do Paraná, Brasil E-mail: jrcampos@utfpr.edu.br

Nilvânia Aparecida de Mello

ORCID: https://orcid.org/0000-0002-5371-0554 Universidade Tecnológica Federal do Paraná, Brasil E-mail: nilvania@utfpr.edu.br

Cristiane Maria Tonetto Godoy

ORCID: https://orcid.org/0000-0001-6150-9976

Universidade Tecnológica Federal do Paraná, Brasil E-mail: guriaccr@hotmail.com

\begin{abstract}
Resumo
O município de São Miguel do Oeste, Extremo Oeste Catarinense, se desenvolveu a partir de uma forte influência de processos migratórios e também através de uma pressão sobre os seus recursos naturais, notadamente as florestas com araucárias. Neste sentido, o presente trabalho tem como objetivo analisar o processo de expansão urbana de São Miguel do Oeste, num contexto sóciotemporal e fatores geomorfológicos, com o intuito de contribuir com o entendimento da relação homem/espaço/tempo na construção da referida cidade. O estudo da morfologia do relevo foi realizado a partir de um Modelo Digital de Elevação (MDE), da qual foram gerados o mapa de declividade, o mapa hipsométrico e os perfis topográficos. A análise espacial e temporal foi realizada através de documentos, mapas históricos e cartas arquivadas na Prefeitura Municipal de São Miguel do Oeste. O início da formação da cidade se deu em área de relevo plano, próximo à cabeceira do Rio Guamirim, e seu período de maior expansão territorial ocorreu na década de 1970, quando o município recebeu inúmeras famílias que emigraram do Rio Grande do Sul. A ruptura do relevo em escarpas erosivas foram os principais condicionantes da atual configuração espacial urbana, o que impulsionou o crescimento vertical da cidade.
\end{abstract}

Palavras-chave: Expansão urbana; Homem; Espaço; Tempo; Modelo digital de elevação.

\begin{abstract}
The municipality of São Miguel do Oeste, West of Santa Catarina state, developed from a hard influence of migratory processes and also through pressure on its natural resources, notably the Araucaria forests. In this sense, the present study aims to analyze the process of urban expansion of São Miguel do Oeste, in a socio-temporal and geomorphological context, in order to contribute to the understanding the man/space/time relationship in the construction of that city. The study of the relief morphology was performed using a Digital Elevation Model (DEM), from which the slope map, the hypsometric map and the topographic profiles were generated. The spatial and temporal analysis was carried out through documents, historical maps and charts filed at the Municipality of São Miguel do Oeste. The beginning of the city's formation was in a flat relief, close to the head of the Guamirim River, and its period of greatest territorial expansion occurred in the 1970s, when the municipality received numerous families who emigrated from Rio Grande do Sul state. the relief in erosive cliffs were the main conditioning factors of the current urban spatial configuration, which boosted the city's vertical growth.
\end{abstract}

Keywords: Urban expansion; Men; Space; Time; Digital elevation model.

\section{Resumen}

El municipio de São Miguel do Oeste, Extremo Oeste Santa Catarina, se desarrolló a partir de la fuerte influencia de los procesos migratorios y también a través de la presión sobre sus recursos naturales, en particular los bosques de Araucaria. En este sentido, el presente trabajo tiene como objetivo analizar el proceso de expansión urbana de São Miguel do Oeste, en un contexto socio-temporal y geomorfológico, con el fin de contribuir a la comprensión de la 
relación hombre / espacio / tiempo en la construcción de esa ciudad. El estudio de la morfología del relieve se realizó mediante un Modelo Digital de Elevación (DEM), a partir del cual se generaron el mapa de pendientes, el mapa hipsométrico y los perfiles topográficos. El análisis espacial y temporal se realizó a través de documentos, mapas históricos y cartas archivadas en el Municipio de São Miguel do Oeste. El inicio de la formación de la ciudad se produjo en una zona de relieve llano, cercana a la cabecera del río Guamirim, y su período de mayor expansión territorial se dio en la década de 1970, cuando el municipio recibió a numerosas familias que emigraron de Rio Grande do Sul. El relieve en acantilados erosivos fueron los principales condicionantes de la configuración espacial urbana actual, que impulsó el crecimiento vertical de la ciudad.

Palabras clave: Expansión urbana; Hombre; Espacio; Hora; Modelo de elevación digital.

\section{Introdução}

Os aglomerados urbanos são fenômenos recentes na história da humanidade, marcados por contextos que originam diversas indagações, sejam elas referentes à sua complexidade, vitalidade ou dinâmica, e que merecem investigações críticas e reflexivas. O urbano é moldado por relações que sofrem transformações cotidianas. Nos últimos anos, além do expressivo aumento no crescimento das cidades, observou-se maior densidade em relação à ocupação dos espaços urbanos que acarretou uma série de mudanças nas relações sociais, culturais e econômicas (Bonette \& Reis, 2021; Fontolan \& Iarozinski Neto, 2021).

Apesar de ter proporcionado avanços significativos, este complexo processo de ocupação dos espaços deixou traços negativos como, por exemplo, apropriações irregulares, poluição visual, riscos a vida e ao meio ambiente. Esse fato agrava-se ainda mais quando a condição do solo e relevo não é favorável à construção de edificações e consequentemente à ocupação humana. As cidades apresentam dinamismo e potencial de expansão, gerando assim um importante desafio quanto à progressão e delineamento da infraestrutura, malha viária e configuração da vida urbana. Por tal motivo, precisam ser interpretadas e compreendidas para que sejam inseridas nesta realidade que marca diversas regiões brasileiras.

No início do século $\mathrm{XX}$, os centros urbanos incorporavam percepções de progresso, inovação, aprimoramentos técnicos, culturais e econômicos em grande escala. Entretanto, essa imagem fora invertida atualmente para desordem e fragmentação socioespacial (Pires, 2008). Enquanto isso, o fim do século XX é marcado por avanços que influenciaram as práticas e o comportamento humano na ocupação do solo e transformações territoriais, estimulando a inclusão de debates acerca do planejamento e gestão urbana. Em outras palavras, a aceleração das mudanças citadinas ocorridas nesse período histórico, proveniente do aperfeiçoamento tecnológico atuante na economia e sociedade, juntamente com a globalização, interferiu diretamente no comportamento social e na maneira pela qual lidam com o espaço e território (Garcia, 2013).

Sob o ponto de vista geomorfológico, as cidades ou aglomerados urbanos caracterizam-se como corpos complexos em expansão espacial, onde o homem, a partir da técnica e da engenharia, se adapta a condição do meio. No Brasil, assim como na maioria dos países em desenvolvimento, o crescimento descontrolado origina formas desordenadas de adaptação da urbanização ao relevo, o que pode gerar riscos ao próprio ocupante e ao meio ambiente (Saadi, 1997). Nos espaços naturais, Modenesi-Gauttieri e Hiruma (2004) identificam como fatores fundamentais para diagnosticar os problemas ambientais e propor o planejamento de intervenções, a compreensão da transformação da paisagem e da relação entre os fatores geomorfológicos nela presentes.

A percepção de tais aspectos, bem como o conhecimento das características do solo como textura, estrutura e consistência, é fundamental para o estabelecimento do seu correto uso. Em áreas mais suscetíveis à erosão e a deslizamentos, que representam potencial de risco, requerem atenção redobrada do poder público. Isto é, a identificação dos fatores favoráveis ou inadequados ao uso e ocupação do solo é imprescindível para o delineamento urbano (Modenesi-Gauttieri \& Hiruma, 2004).

Considerando o desenvolvimento das cidades pertencentes ao território brasileiro e as consequências históricas provenientes da utilização espacial inapropriada, observa-se como meio de reverter essa situação, a intervenção do planejamento dos locais propícios à expansão urbana, principalmente aquelas que apresentam peculiaridades ambientais 
(Garcia, 2013). "O planejamento é a preparação para a gestão futura, buscando-se evitar ou minimizar problemas e ampliar margens de manobra; e a gestão é a efetivação, ao menos em partes [...] das condições que o planejamento feito no passado ajudou a construir" (Souza, 2015, p. 46). Para o autor, essa idealização não pode ser abdicada, pois equivaleria a traçar caminhos incompatíveis com a vida da sociedade, independente do modelo e complexidade.

Desta forma, o planejamento urbano visa à projeção de uma cidade, ocupação harmônica, progresso e desenvolvimento. "O urbano não é uma realidade acabada, mas um horizonte de transformações territoriais, sociais, políticas e econômicas que se difunde em fluxos materiais e imateriais" (Rodrigues, 2008, p. 114).

Diante do exposto, este trabalho tem como objetivo analisar o processo de expansão urbana da cidade de São Miguel do Oeste, Extremo Oeste Catarinense, tendo em vista aspectos temporais e fatores geomorfológicos, de modo a contribuir com o entendimento da relação homem/espaço/tempo. Além disso, baseia-se na hipótese de que, em função de uma maior pressão social, uma cidade pode expandir-se para áreas fisicamente impróprias para a construção civil. Tal processo é possibilitado pela própria capacidade do homem em se adaptar ao meio e pela transformação das técnicas e do pensamento arquitetônico.

\section{Materiais e métodos}

\section{1 Área de estudo}

O presente trabalho foi realizado na área urbanizada de São Miguel do Oeste, município representativo do Extremo Oeste Catarinense no que se refere à área, população, densidade demográfica, geomorfologia, e demais características peculiares da região. O referido município, de acordo com o Instituto Brasileiro de Geografia e Estatística (2018), possuía uma área territorial de $234 \mathrm{~km} 2 \mathrm{em}$ 2016, densidade demográfica de 155,12 hab/km2 em 2010, com 36.306 habitantes (censo de 2010) sendo 32.065 residentes da área urbana e 4.241 residentes da área rural, e população estimada de 39.793 habitantes em 2017, situando-se na região Extremo Oeste do Estado de Santa Catarina, Brasil (Figura 1).

Figura 1 - Localização da área de estudo.

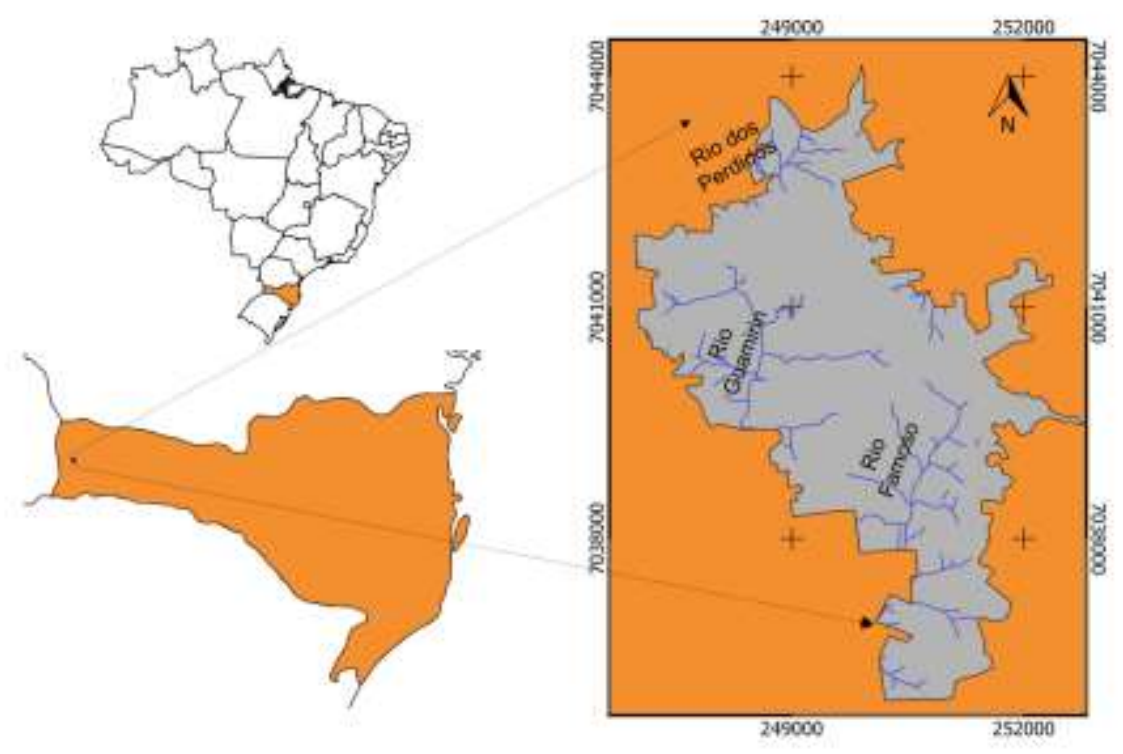

Fonte: Autores (2021).

Colonizada basicamente por famílias italianas, alemãs, mestiças e caboclas, a referida cidade foi elevada à categoria de município em 1953. Sua economia, desde então, foi baseada predominantemente por atividades relacionadas à produção agrícola (São Miguel do Oeste, 2009). 
O município de São Miguel do Oeste limita-se territorialmente com os municípios de Barra Bonita, Romelândia, Flor do Sertão, Paraíso, Bandeirante, Guaraciaba e Descanso. Com altitude média de $645 \mathrm{~m}$ e distando 672 km de Florianópolis (capital do Estado), é acessado por importantes rodovias estaduais e federais, dentre elas a BR 282, BR 163 e SC 493 (São Miguel do Oeste, 2009).

O relevo é marcado pelo planalto dissecado do rio Iguaçu, cujas altitudes seguem os vales do rio Uruguai e seus afluentes, abrangendo especialmente os vales dos rios Peperi-Guaçu e das Antas. A temperatura média oscila entre 18 e $20^{\circ} \mathrm{C}$, podendo atingir $40{ }^{\circ} \mathrm{C}$ no verão, e temperaturas negativas no inverno, caracterizando clima Cfa pela Classificação de Koppen. Os verões são quentes e durante o inverno as neves são raras e as geadas comuns. (São Miguel do Oeste, 2009).

A umidade relativa no município é de $75 \%$, elevando-se conforme a proximidade do litoral catarinense, e as precipitações médias correspondem a 2.200 e 2.400 milímetros por ano. Apesar de existir estiagem, não há um período definido para as ocorrências de secas (São Miguel do Oeste, 2009).

\subsection{Análise do relevo}

A análise da morfologia do relevo foi realizada a partir de um Modelo Digital de Elevação (MDE), originalmente gerado em 2000 pela NAZA na Missão Shuttle Radar Topography Mission (SRTM) com resolução espacial de 90m. Em seguida, esses dados foram processados pelo Instituto Nacional de Pesquisa Espacial (INPE), sendo disponibilizadas com resolução de 30m. Através desse MDE foram gerados o mapa de declividade, o mapa hipsométrico e os perfis topográficos, com o intuito de analisar a configuração do relevo na área em questão (Silva, Marques \& Delgado, 2012).

$\mathrm{Na}$ área de estudo do município de São Miguel do Oeste, o mapa de declividade foi dividido em cinco classes de declividade, sendo elas: 0 a 12\%, 12 a 20\%, 20 a 30\%, 30 a 47\% e acima de 47\%. Tais classes correspondem à proposta de classificação pregada por Riffel (2012), adaptada a partir da metodologia do autor De Biasi (2011), devido atualizações nas legislações urbanísticas e ambientais. Esses valores foram assim justificados: 0 a 12\% limite urbano, industrial e de máxima utilização da mecanização na agricultura; 12 a 20\% solo com moderada suscetibilidade à erosão; 20 a 30\% limite máximo para urbanização (sem restrições) conforme o disposto na Lei nº 6.766 de 1979; 30 a 47\% limite máximo de corte raso (exploração permitida se sustentada por cobertura de floresta) e acima de $47 \%$ que corresponde à preservação total do solo (Área de Preservação Permanente).

O mapa hipsométrico, por sua vez, foi estruturado com variação de elevação a cada $31 \mathrm{~m}$, e a partir dos dados do MDE foram desenvolvidos perfis topográficos com o intuito de analisar as variações no relevo e a identificação de áreas impróprias à construção de edificações. Tais perfis foram elaborados utilizando gráficos com coordenadas a cada $2.000 \mathrm{~m}$ de distância e $30 \mathrm{~m}$ de elevação. O processamento do MDE e confecção dos mapas foram executados com o software Quantum Gis 2,18.

\subsection{Análise Espacial e Temporal}

A análise do processo de expansão da área urbanizada do município de São Miguel do Oeste foi realizada pelo estudo de documentos e mapas históricos (que são registros da formação do tecido urbano e configuração da sua paisagem, juntamente com o uso e ocupação do solo), bem como de cartas arquivadas no acervo da Prefeitura Municipal de São Miguel do Oeste. Essas cartas foram digitalizadas, georreferenciadas e vetorizadas, sendo as áreas de expansão correspondentes a cada década (de 1950 a 2010). A definição do recorte temporal foi definida pela caracterização da década de emancipação do município e surgimento dos primeiros aglomerados urbanos, até os dias atuais. O sistema de coordenadas adotado foi o UTM (Universal Transverse Mercator) e o DATUM WGS 1984, zona 22S. Assim como para o estudo do relevo, o software Arc Gis 10.1 também foi utilizado nos aspectos espaciais e temporais. 


\section{Resultados e Discussão}

As cidades foram marcadas por avanços que interferiram drasticamente na configuração do espaço natural, resultando na intensificação da urbanização pela ação do homem. Nesse cenário, destacam-se potencialidades e fragilidades que ordenaram tal processo. A formação de São Miguel do Oeste foi norteada por fatores sociais e geomorfológicos, bem como pela disponibilidade de recursos naturais. Essas particularidades merecem estudos específicos e aprofundados, por refletirem no futuro do planejamento urbano e na relação do homem com a natureza.

\subsection{Caracterização do relevo da área de estudo}

A hidrografia, juntamente com as condições topográficas do relevo, são aspectos condutores da formação, crescimento e desenvolvimento de muitas cidades, inclusive de São Miguel do Oeste, que se constituiu as margens de um rio, denominado rio Guamirim.

As águas do rio Guamirim foram indispensáveis para a vida das muitas famílias italianas, alemães, mestiças e caboclas que aos poucos se instalavam na antiga Vila Oeste, nome do primeiro povoamento que deu origem ao município de São Miguel do Oeste. A nascente possuía água de qualidade, além de ser cercada por árvores, pinheiros, canelas e grápias que cobriam o leito do rio com sua sombra (Spenassatto, 2008).

A área urbanizada do município de São Miguel do Oeste está inserida em três principais bacias hidrográficas: bacia do rio dos Perdidos, localizada na região norte; bacia do rio Guamirim, localizada na região central e bacia do rio Famoso, localizada na região Sudeste (São Miguel do Oeste, 2009). As demais bacias hidrográficas: bacia do rio Parda, bacia do rio Sanga Nova, bacia do lajeado da Divisa, bacia do rio Veadinho e bacia do rio Jacutinga (Figura 2), também fazem parte deste perímetro, mas ocupam menores proporções, em virtude da elevada declividade nessas bacias (Figura 3).

O entalhamento diferenciado do relevo, proporcionado pelos rios da região em estudo, foi fundamental para a atual configuração espacial do município de São Miguel do Oeste que se concentrou nas bacias dos rios Guamirim, Perdidos e Famoso (Figura 2). Dentre as três bacias supracitadas, a bacia do rio dos Perdidos foi a que apresentou relevo mais declivoso, conforme indicado na Figura 3, com predomínio de valores entre 12 e 20\%, podendo chegar de 20 a 30\%, o que já representa o limite máximo aceitável para urbanização (Riffel, 2012). Devido à forte influência do basalto, os solos são muito argilosos e em condição de elevada declividade, assim, as encostas apresentam-se instáveis, o que dificulta a expansão da cidade nessa região. 


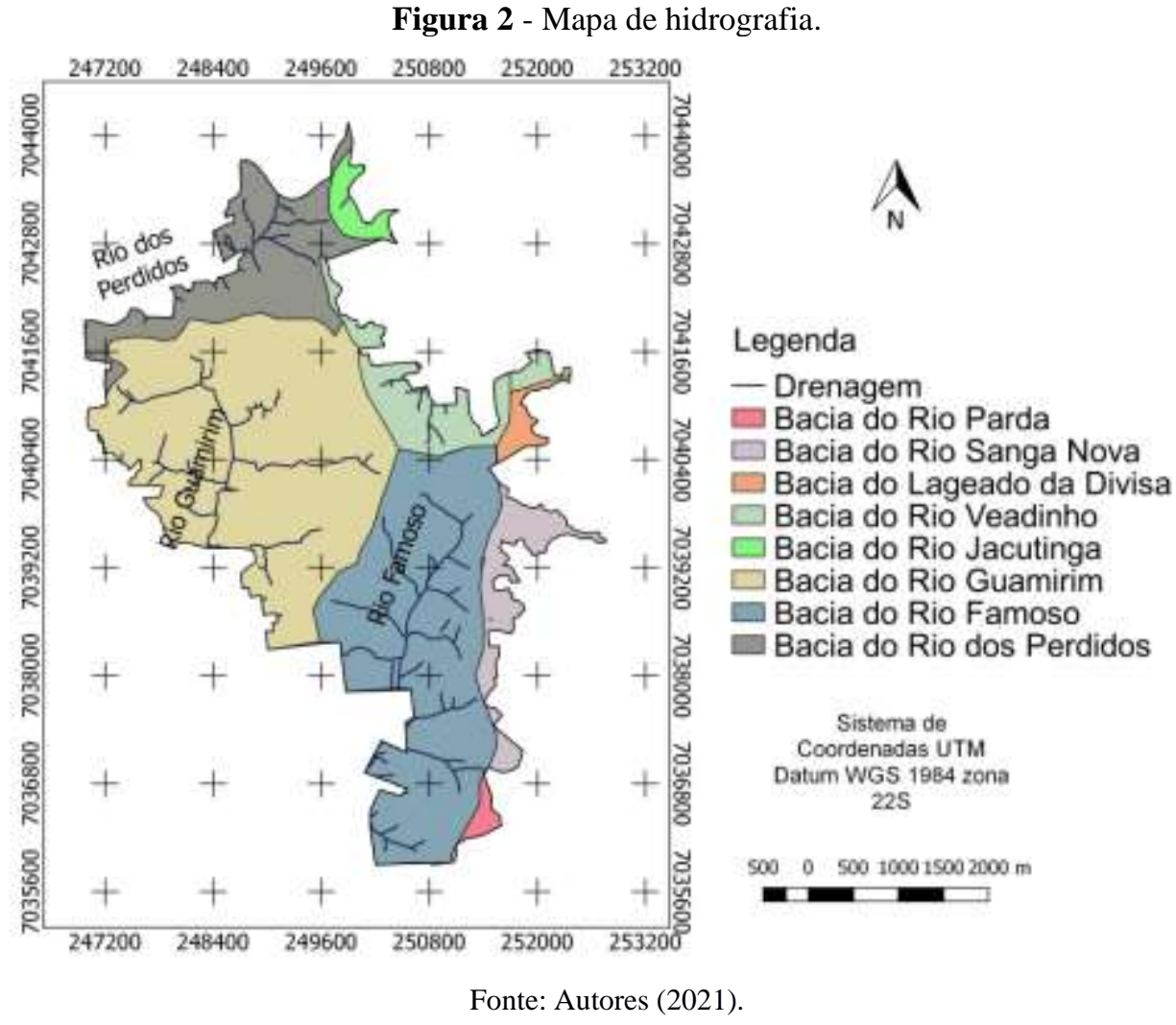

Na bacia do rio Guamirim, por sua vez, há predomínio de relevo mais suave com declividade variando entre 0 e $12 \%$. Nessa condição, mesmo se tratando de solos muito argilosos, as encostas possuem maior estabilidade, o que facilita o tráfego de pessoas e de máquinas, contribuindo para a construção de novas edificações. Semelhante à bacia do rio Guamirim, a bacia do rio Famoso também exibe solos muito argilosos com relevo predominantemente suave, cujas declividades predominam entre 0 e $12 \%$.

Nas áreas onde o relevo é menos declivoso, a ocupação humana é possibilitada pela facilidade de locomoção e por representar menor gasto energético, diferentemente de áreas mais declivosas, cuja ocupação exige técnicas de engenharia e inovações construtivas, bem como representam maior gasto energético ao trabalho humano. Além disso, evidencia-se que em locais com expressiva declividade, são altos os índices de deslizamentos, desmoronamentos e erosões, devido às práticas de remoção da camada vegetal e substituição da massa verde (permeável) por superfícies de concreto (impermeáveis). 


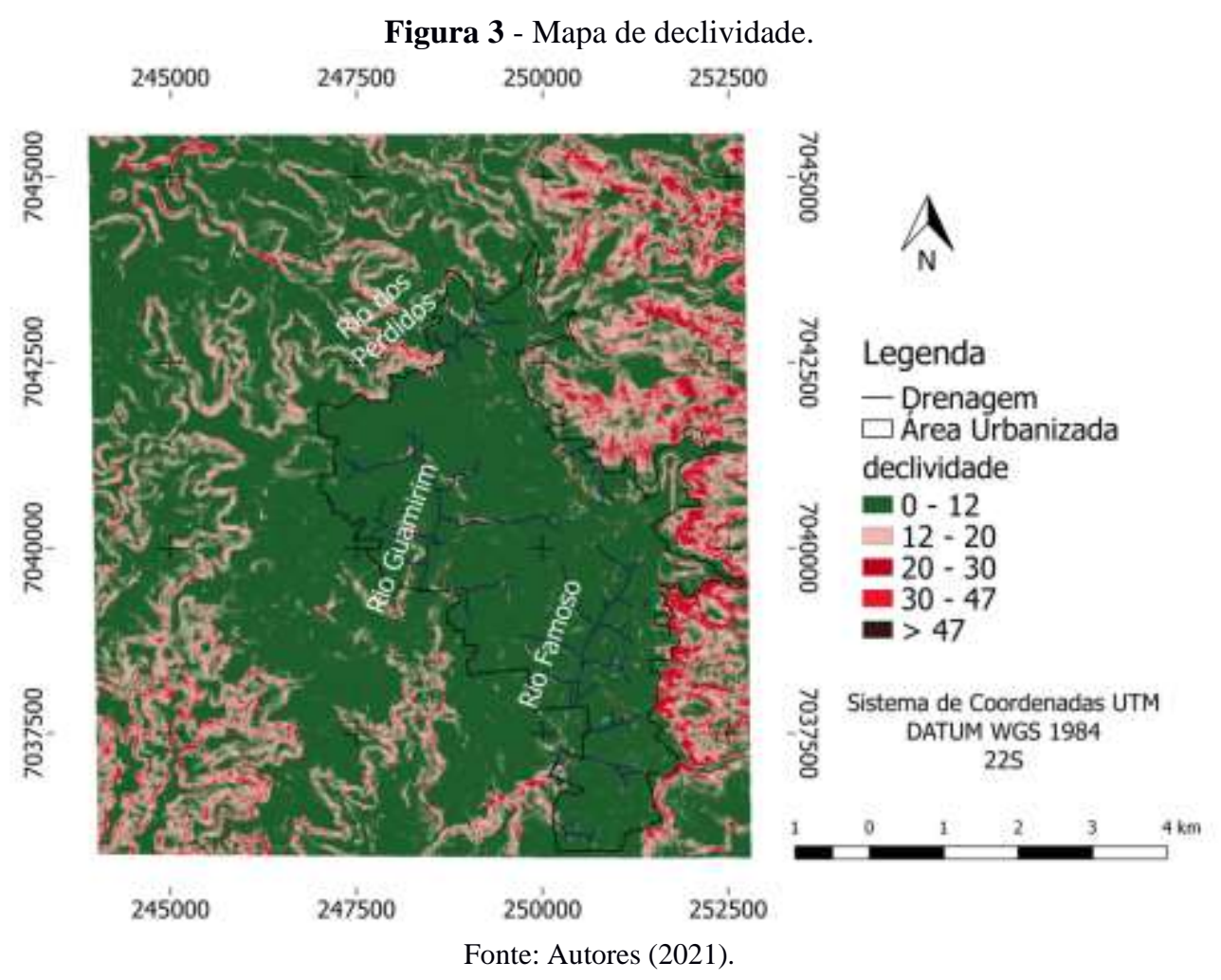

Nesse contexto, vale ressaltar a importância do gradiente topográfico para a expansão da cidade. No mapa hipsométrico, representado na Figura 4, destaca-se a estreita relação entre os limites da área urbanizada e as escarpas erosivas que compõem as principais bacias que circundam a área urbanizada do município.

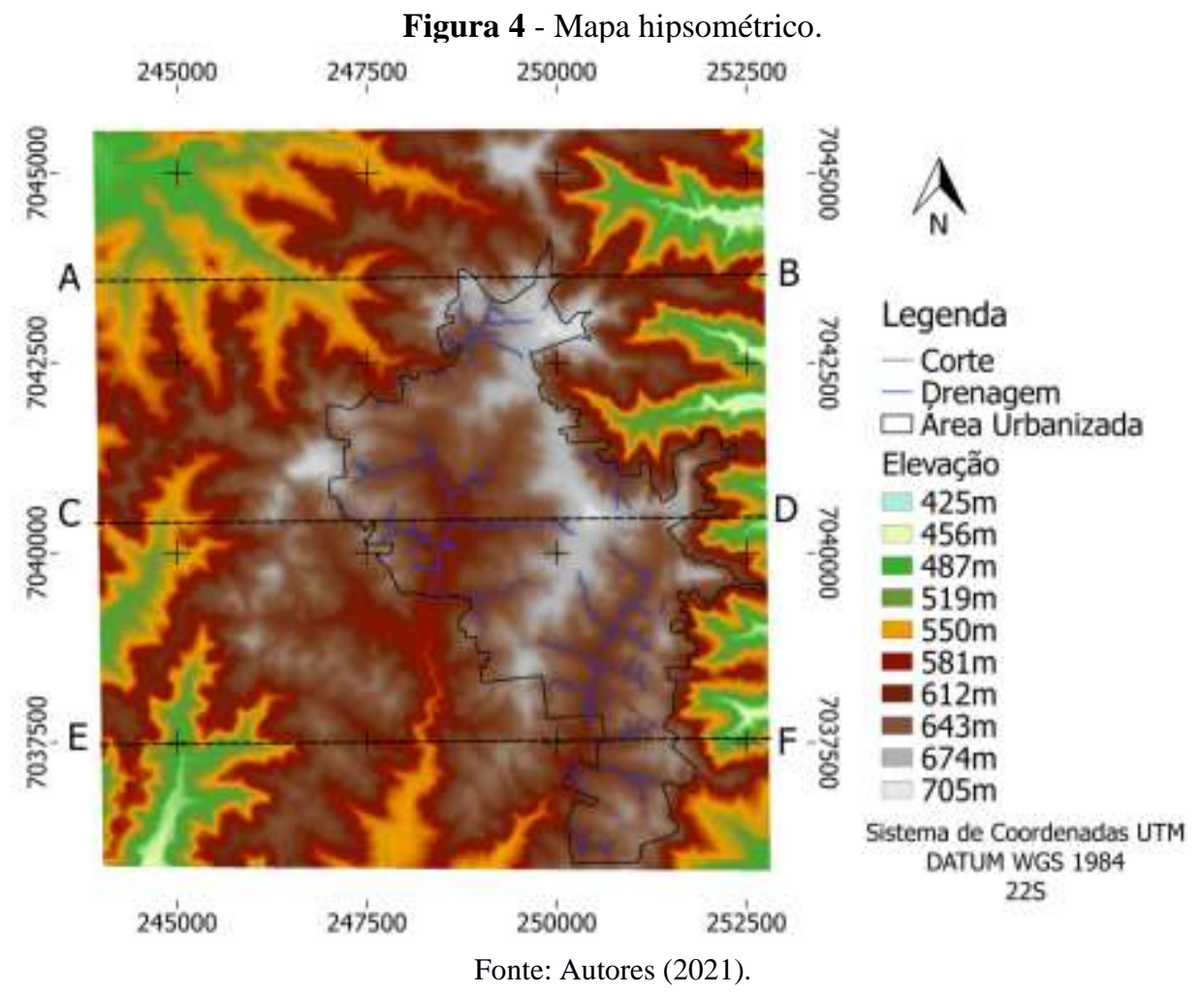


No perfil AB (Gráfico 1) é possível observar dois níveis topográficos principais. O primeiro apresenta cotas entre $520 \mathrm{~m}$ e $570 \mathrm{~m}$ (diferença de 50m), enquanto o segundo apresenta cotas entre $620 \mathrm{~m}$ e $680 \mathrm{~m}$ (diferença de $60 \mathrm{~m}$ ). A comunicação entre tais patamares é interrompida por uma escarpa erosiva no sentido oeste, que simboliza um obstáculo de expansão da cidade, pelas dificuldades de transposição nessa direção.

Gráfico 1 - Perfil AB.

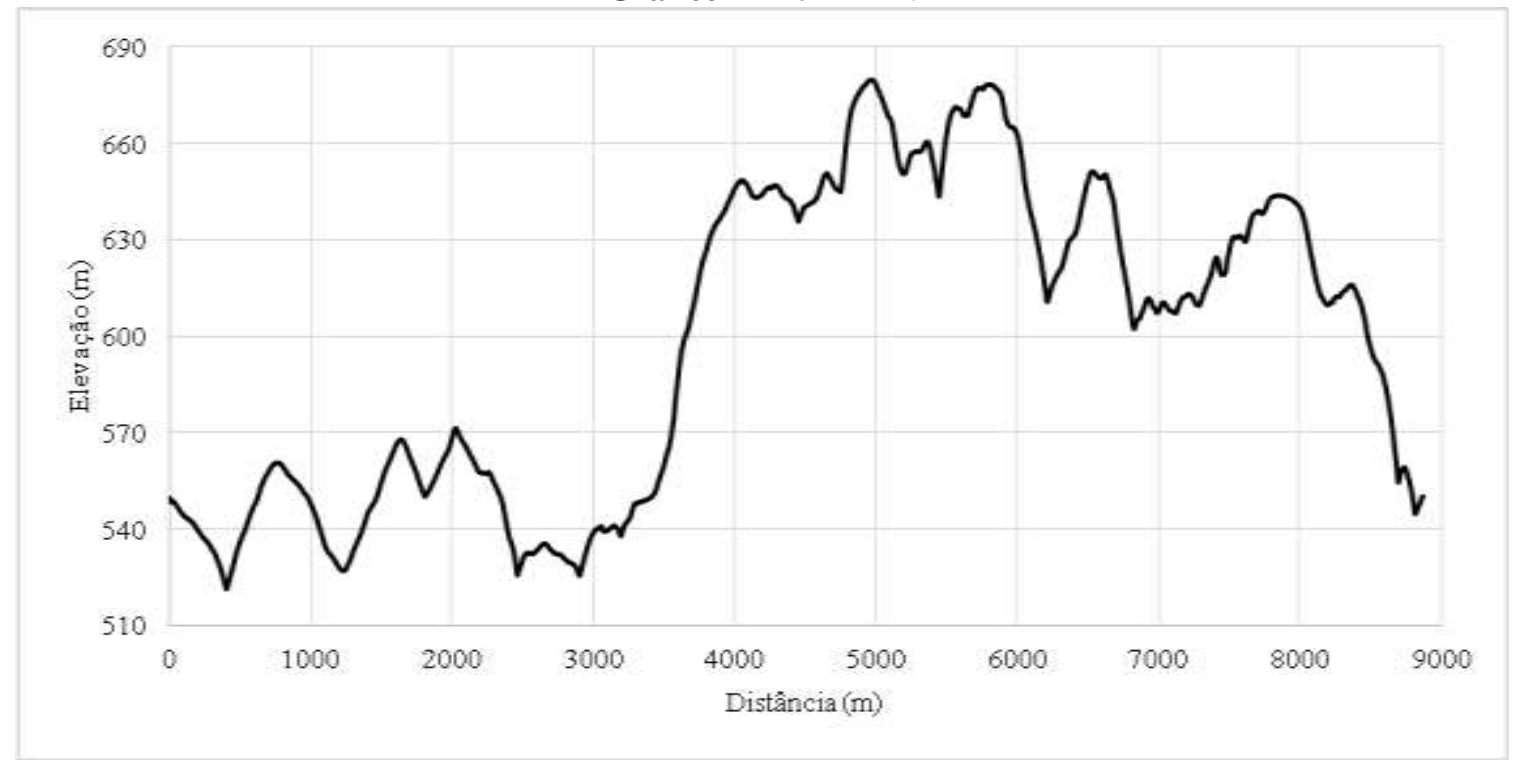

Fonte: Autores (2021).

Essa escarpa erosiva no sentido oeste do perfil $\mathrm{AB}$ caracteriza uma paisagem marcada pela presença de fundos de vale, cuja declividade expressiva dificulta a continuidade da malha viária existente e consequentemente o uso do solo. Além disso, a ocupação desse relevo com novas edificações somente seria possível através da utilização de técnicas de engenharia que garantissem a sustentação estrutural das obras sem comprometer sua qualidade funcional e arquitetônica. Nesse contexto, tais intervenções, sem a devida compactação do solo com camadas de vegetação, induziriam práticas erosivas e de deslizamento, vistas como impactos ambientais.

No perfil CD (Gráfico 2), foram observados três patamares, sendo o primeiro na cota de $500 \mathrm{~m}$; o segundo entre $530 \mathrm{~m}$ e $620 \mathrm{~m}$ e o terceiro patamar entre as cotas $610 \mathrm{~m}$ e $700 \mathrm{~m}$. De maneira geral, o terceiro patamar apresenta variações mais suaves de topografia, quando comparados ao perfil AB, e representa o local de início da formação da cidade de São Miguel do Oeste. As extremidades desses patamares centrais são cercadas por relevos acidentados, principalmente no sentido oeste - leste. 


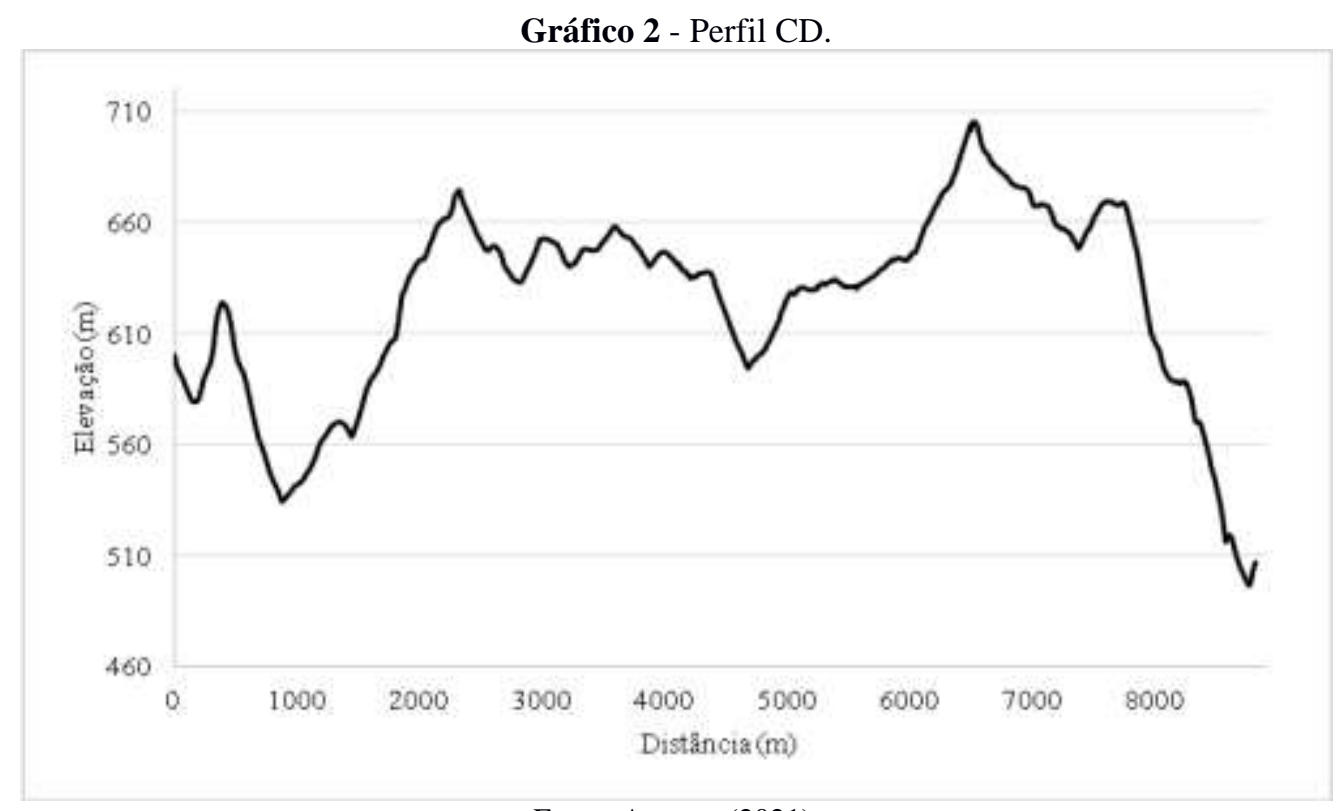

Fonte: Autores (2021).

A Figura 5 demonstra parte do espaço urbano da cidade de São Miguel do Oeste edificado em áreas de relevo suave, o que facilitam o processo construtivo e de uso do solo, bem como a implantação da infraestrutura e traçado viário para atender as demandas populacionais.

Figura 5 - Vista da área central do perfil CD.

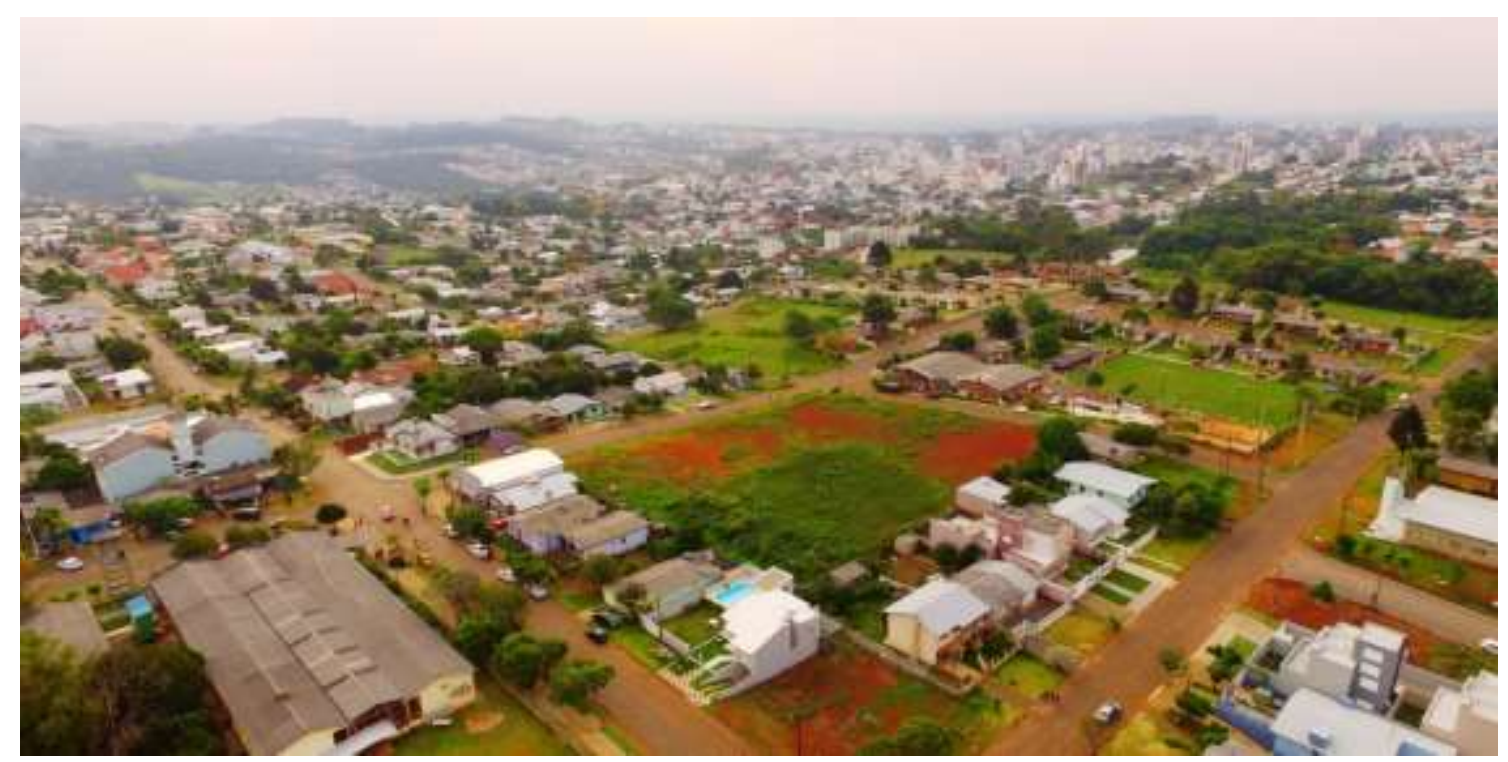

Fonte: Autores (2021).

Na direção leste do perfil CD (visualizado na Figura 6), analisa-se escarpa erosiva configurando áreas de fundo de vale, juntamente com vegetação nativa e cursos d'água que impedem a expansão da cidade de São Miguel do Oeste nesse sentido. Por tal motivo, a sequência da conformação urbana segue para o lado oeste, como observado na Figura 7, cujas características topográficas são favoráveis. 
Research, Society and Development, v. 10, n. 14, e300101421870, 2021

(CC BY 4.0) | ISSN 2525-3409 | DOI: http://dx.doi.org/10.33448/rsd-v10i14.21870

Figura 6 - Expressiva declividade no sentido leste do perfil CD.

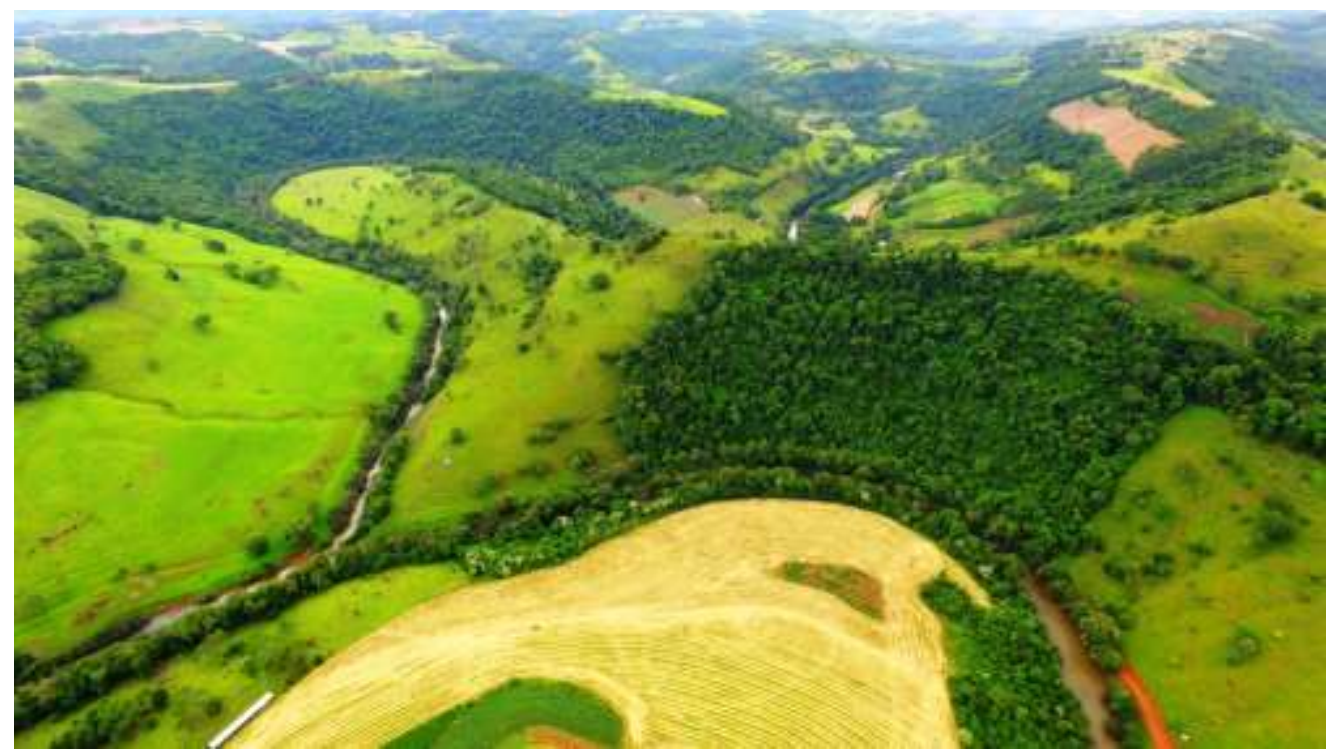

Fonte: Autores (2018).

Figura 7 - Expansão urbana no sentido oeste do perfil CD.

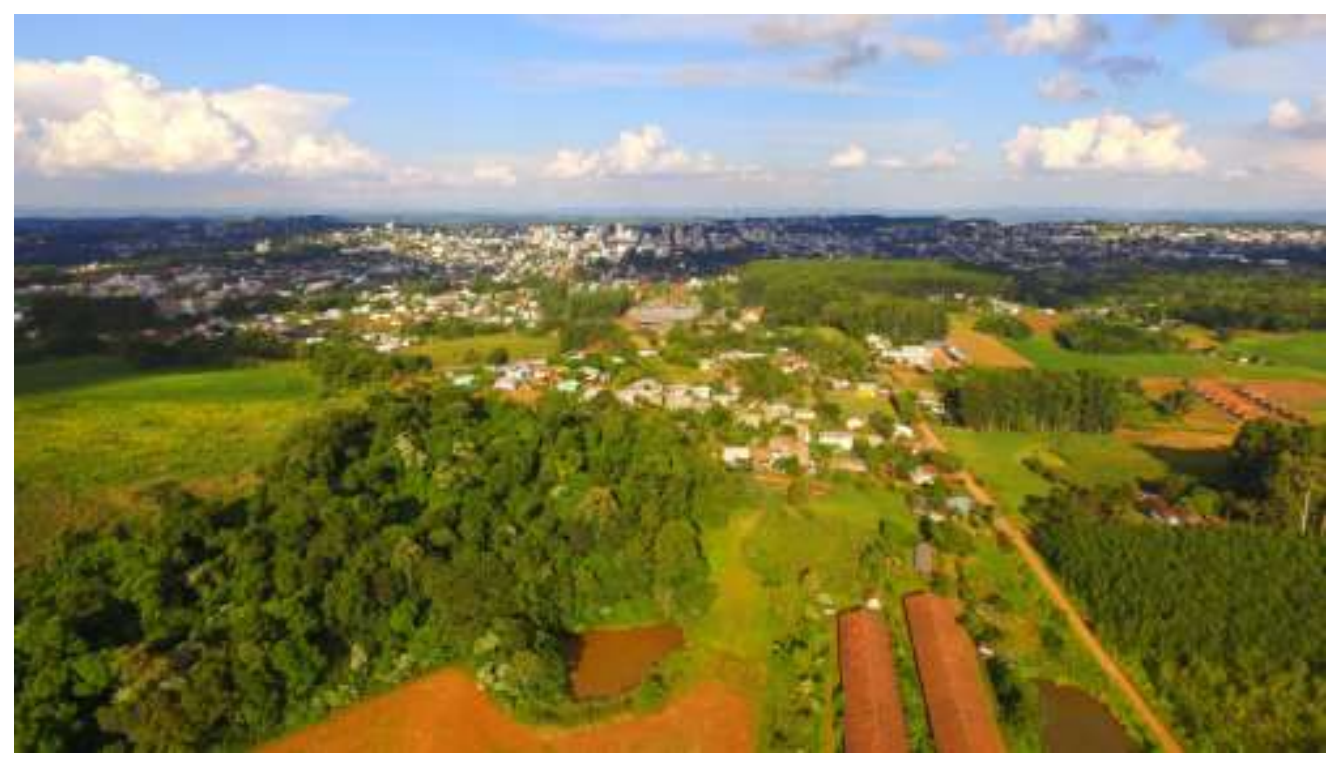

Fonte: Autores (2018).

Por fim, no perfil EF (Gráfico 3), observam-se dois entalhamentos importantes para o presente estudo. O primeiro, localizado na parte mediada do gráfico, representa o entalhamento do rio Guamirim e sua maior profundidade, relacionado ao fato de encontrar-se mais a jusante da região central da cidade. $\mathrm{O}$ segundo entalhamento, localizado a leste, representa o entalhamento do Rio Famoso que também simboliza ambiente inóspito para a expansão urbana, pela sua suscetibilidade a erosão e pela dificuldade de deslocamento e transporte, além da necessidade de técnicas de construção civil específicas. 
Gráfico 3 - Perfil EF.

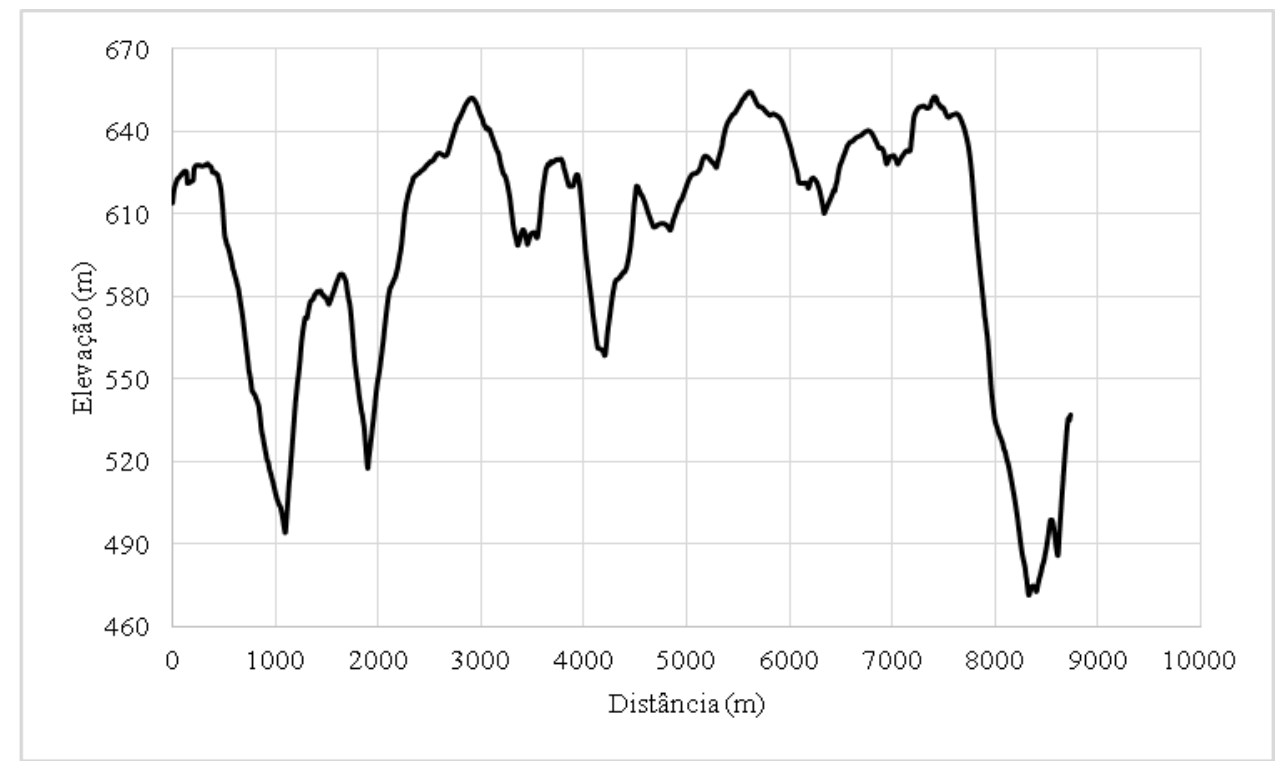

Fonte: Autores (2021).

A área de estudo concentra-se em espaços com cotas elevadas, mas com variações mais sutis em relação à cota e a forma do relevo que, nas partes mais elevadas são predominantemente colineares. De um modo geral, essa diferença de declividade torna-se acentuada na direção leste do perímetro demarcado no mapa de declividade e mapa hipsométrico, seguindo para regiões de fundo de vale, o que induz à baixa concentração de edificações e consequentemente da urbanização.

Assim, visualiza-se que nos relevos com expressiva diversificação de cotas há menores concentrações populacionais, por demandarem de técnicas e tecnologias construtivas que garantam a estabilidade das estruturas e o atendimento ao disposto nas legislações em vigor. Nos casos das ocupações existentes nesses trechos citados, prevalecem famílias com baixo poder aquisitivo e/ou migrantes sem condições financeiras de adquirir outros imóveis. Desta forma, considera-se que as características topográficas dos municípios são relevantes por nortearem a direção e centralidade dos aglomerados urbanos.

\subsection{Modelo de expansão da área de estudo por décadas}

A década de 1950 marca o início da formação do município de São Miguel do Oeste. As primeiras construções foram executadas na cabeceira do rio Guamirim e em relevo com declividades entre 0 e 12\% (Figura 8), não representando significativas limitações para a locomoção. É importante ressaltar que nesse período, o transporte de pessoas e materiais era realizado em lombos de burros e cavalos, cuja topografia era considerada um fator preponderante. Na ocasião, a população total correspondia a 12.374 habitantes, sendo 9.741 habitantes da zona rural $(78,72 \%)$ e 2.633 da zona urbana (21,28\%), segundo estimativas do Censo Demográfico do Estado de Santa Catarina realizado pelo Instituto Brasileiro de Geografia e Estatística (1955).

Na década de 1960 a expansão dos loteamentos ocorre no sentido norte e sul (o equivalente a 0,89 km2) (Figura 8), mesmo sentido do rio Guamirim, e em ambiente com declividade entre 0 e 12\%. Além disso, tais ocupações foram contornando uma das maiores vias da cidade até os dias atuais e cuja influência é visível na trafegabilidade e permeabilidade da circulação. Assim, contempla um aumento total de 6.985 habitantes em relação à década de 1950.

A década de 1970, por sua vez, corresponde ao momento de maior expansão urbana em termos estatísticos, isto é, São Miguel do Oeste cresce 3,42 km2 (Figura 8), influído pelo fenômeno "êxodo rural", que aos poucos interferiu em diversas regiões do país. Nessa época, evidencia-se a expansão urbana em todas as direções, incluindo nas áreas mais declivosas e 
instáveis sob o ponto de vista geológico. Essas áreas consideradas impróprias do ponto de vista da construção civil, foram utilizadas predominantemente por famílias de baixa renda e por imigrantes vindos de outras regiões do país, especialmente do Estado do Rio Grande do Sul. Em tal período, observa-se também a descontinuidade das ocupações formando os vazios urbanos (principalmente ao sul e leste).

Figura 8 - Expansão urbana da área de estudo da década de 1950 a 1980.
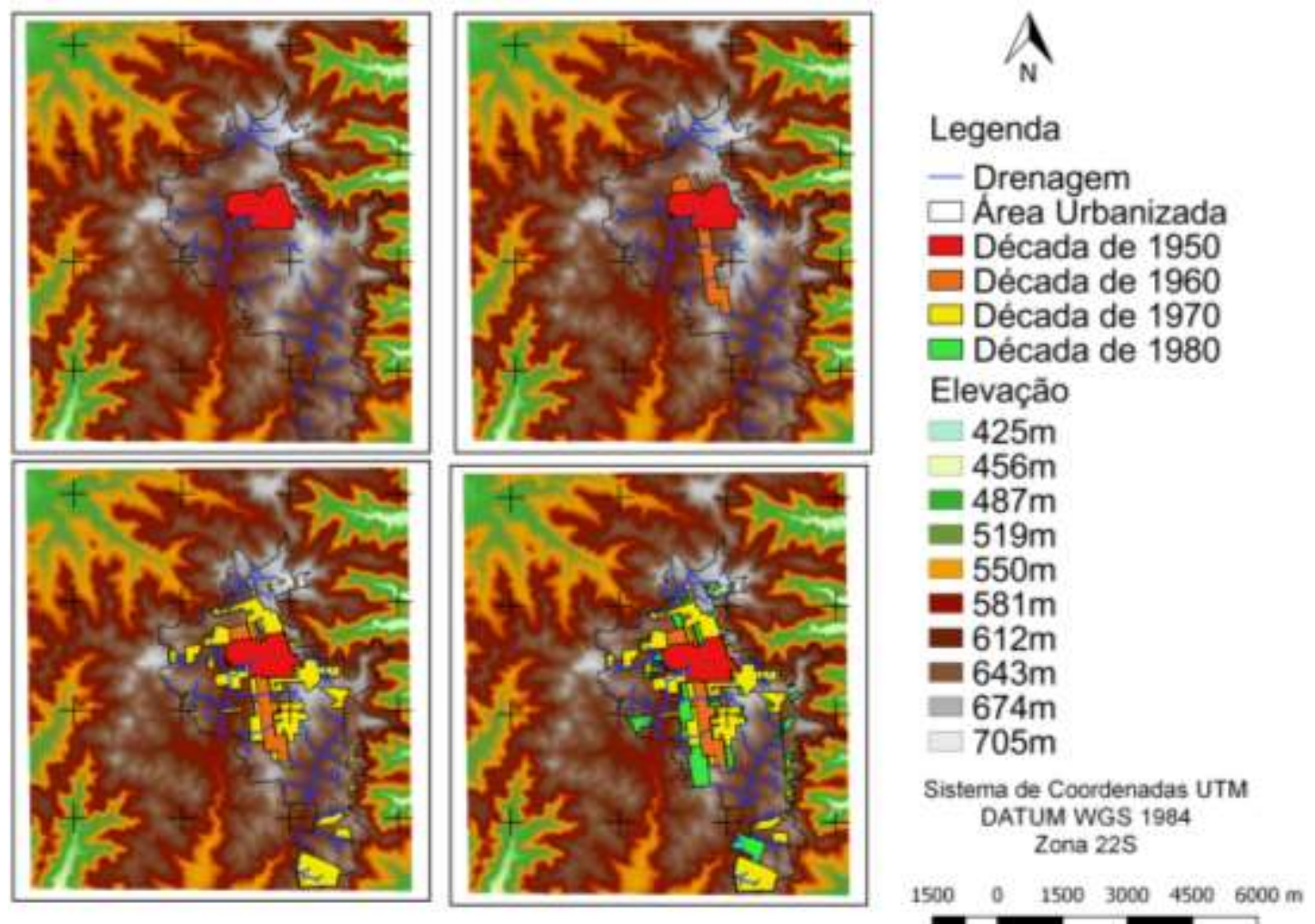

Fonte: Autores (2021).

A partir da década de 1970, o planejamento e a ocupação do espaço urbano emergem não somente em São Miguel do Oeste, mas também em todo o território nacional. Em diversas cidades brasileiras, triplicam o número de habitantes e de área territorial. "Tal fato é agravado com o intenso processo migratório que dá uma nova feição à cidade, além de inverter a relação rural/urbano" (Wollf, 2008, p. 170).

A década de 1980 é caracterizada pela migração em larga escala, maior crescimento populacional (aumento de 13.417 habitantes em relação à década de 1970), e o segundo melhor avanço territorial com 1,69 km² (Figura 8). De acordo com dados do Instituto Brasileiro de Geografia e Estatística (2016), da população total de 35.772 habitantes, 18.790 pertenciam à zona urbana e 16.982 à zona rural, 52,53\% e 47,47\% respectivamente. Esses valores refletem o intenso deslocamento do campo para a cidade, por ser a primeira ocasião em que os índices demográficos urbanos superam os rurais, bem como a chegada de indivíduos provenientes de outros municípios. Durante essa década, prevalecem pequenos loteamentos dispersos, geralmente contíguos aos já existentes e muitas vezes preenchendo os vazios urbanos.

Ao invés da mudança brusca proveniente da migração, o campo e a cidade devem estar relacionados no tempo e espaço, devido às diferenças socioespaciais das regiões do país, isto é, não têm oposição, mas complementaridade, alerta Rodrigues (2008), seguindo este raciocínio crítico.

Na década de 1990, percebe-se um processo de ocupação semelhante à década anterior, com novos loteamentos sendo criados, porém, em menor proporção $\left(0,86 \mathrm{~km}^{2}\right)$. É assinalada pelo acentuada urbanização e declínio do êxodo rural. Enquanto 
isso, na década de 2000 ocorre uma estagnação das taxas de migração e urbanização, além da brusca queda da expansão, com apenas $0,05 \mathrm{~km}^{2}$, devido à saturação de lotes oriundos dos períodos antecedentes e pela alta demanda de exigências legais, inclusive quanto à pavimentação, licenciamento ambiental e limitação de declividade para o uso e ocupação do solo.

Vale ressaltar que muitas das legislações citadas foram instauradas em décadas anteriores, porém, passaram a vigorar no município a partir da década de 2000, e em determinados casos foram atualizadas em períodos posteriores. Tais informações são visíveis no Gráfico 4, ao demonstrar a redução de 11.672 habitantes da zona rural em comparação à década precedente, e um aumento irrisório de 1.754 moradores na zona urbana.

Gráfico 4 - População urbana e rural do município de São Miguel do Oeste.

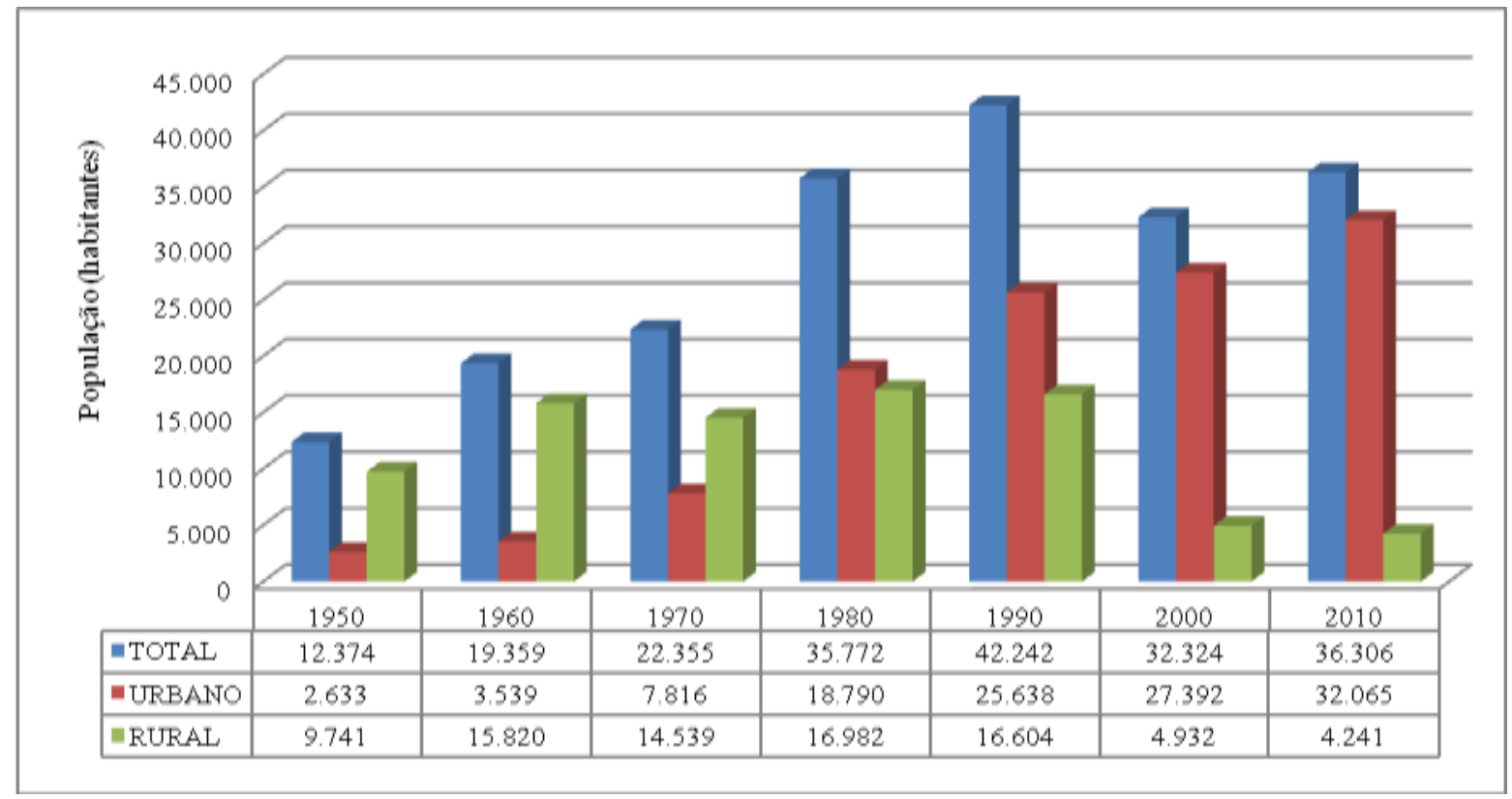

Fonte: Instituto Brasileiro de Geografia e Estatística (2016), com adaptações dos autores (2021)

Conforme o Diagnóstico do Plano Diretor Municipal (São Miguel do Oeste, 2009), nessa época também ocorreu um intenso impacto originário da falta de opções de emprego na cidade de São Miguel do Oeste, procedendo no deslocamento expressivo da população do interior para outros municípios, especialmente a faixa etária jovem.

Em números, a comparação da taxa de criação de empresas e de empregos em São Miguel do Oeste de 2004 a 2008, é representada por uma taxa média de 2,2\% e 7,9\%, respectivamente, ao ano (Serviço Brasileiro de Apoio às Micro e Pequenas Empresas, 2010). Os valores referentes à década de 2000 tornam-se ainda mais preocupantes quando há comparação do pessoal ocupado assalariado da década de 2000 com a década subsequente, devido à expressiva disparidade visualizada nos dados do Instituto Brasileiro de Geografia e Estatística (2007).

A falta de opções de emprego na cidade em questão foi influenciada pela mudança política a nível nacional ocorrida na década de 1990, que segundo Sugai (2015) resultou na redução das ações trabalhistas e sindicais, rígidas medidas da política econômica, desemprego, favorecimento aos grupos de elite, aumento da pobreza e ausência de políticas sociais compensatórias, induzindo a intensificação dos problemas que assolam as áreas urbanas brasileiras. Assim, a carência de políticas habitacionais nos governos neoliberais também inibiu o surgimento de novos loteamentos, refletindo nesse contexto até o final dos anos 2000.

Por fim, na década de 2010, o mercado habitacional reaquece com o surgimento de incentivos do governo federal, focalizados em políticas compensatórias para atender as demandas sociais, de inclusão e redução da pobreza (Sugai, 2015). 
Nessa ocasião, a autora supracitada relata que dentre tais iniciativas, a valorização real do salário mínimo, previdência social rural e urbana, geração de empregos formais, e principalmente o Programa Minha Casa Minha Vida, foram significativas para a proteção social trabalhista, alteração do perfil socioeconômico da população, redução do índice de pobreza, aumento do consumo, fortalecimento do mercado interno, e especialmente estímulo na aquisição de terrenos para a construção da casa própria.

Os acontecimentos mencionados elucidaram a produção de novos loteamentos (o equivalente a $0,44 \mathrm{~km}^{2}$ ) na referida década, que com a vigência de legislações ambientais e municipais mais rígidas, tornaram os usos e as ocupações urbanas mais distantes dos cursos d'água, Áreas de Preservação Permanente e das áreas consideradas impróprias para a construção civil. A expansão urbana de São Miguel do Oeste da década de 1990 a 2010 pode ser observada através da Figura 9, representada por manchas esquemáticas que mapeiam os principais aglomerados urbanos desses respectivos períodos.

Figura 9 - Expansão urbana da área de estudo da década de 1990 a 2010.
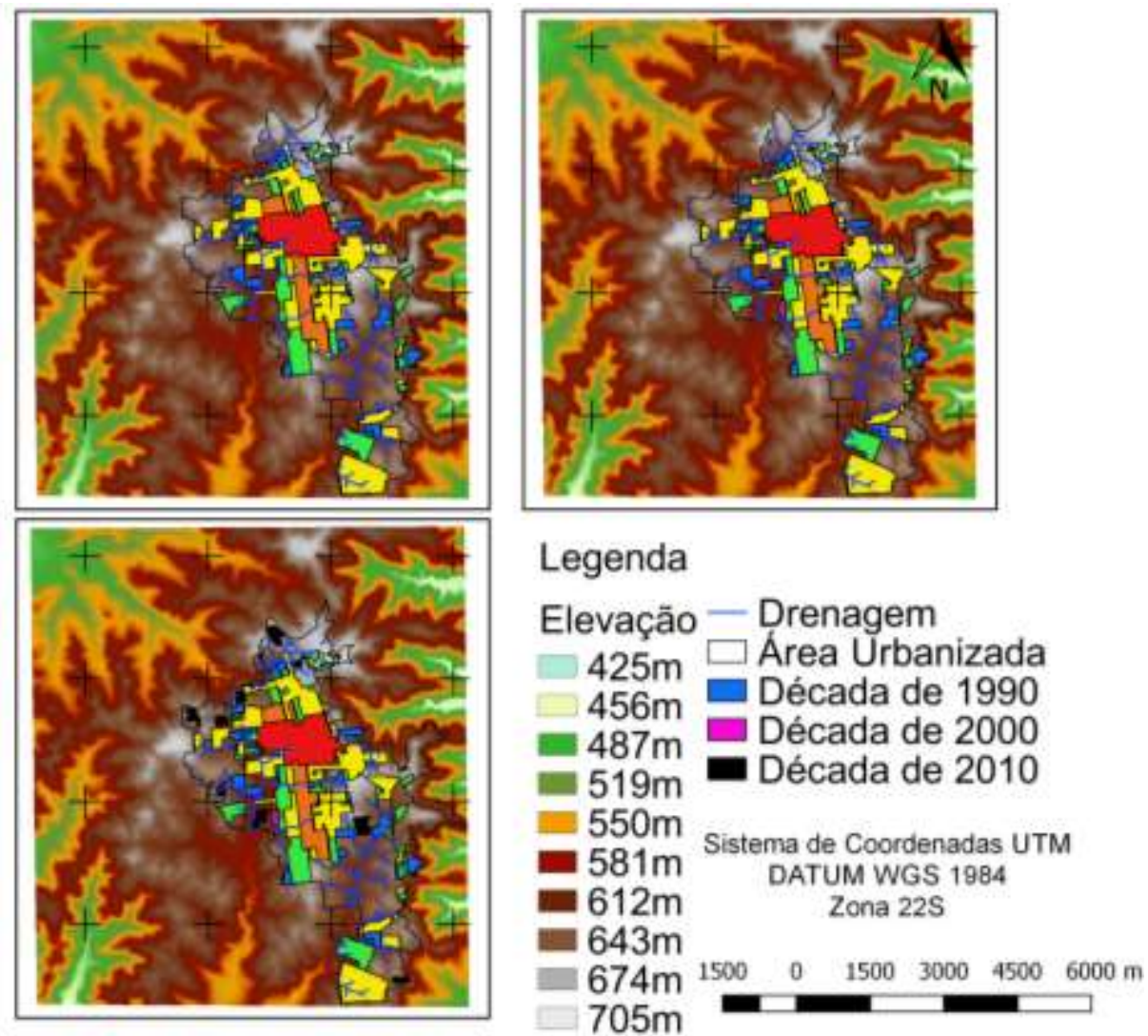

Fonte: Autores (2021).

A partir dessa explanação, compreende-se que a configuração do traçado viário da cidade de São Miguel do Oeste, representada pela disposição das ruas, quadras e lotes, foi ordenada e disposta proporcionalmente ao sentido de expansão urbana ao longo das décadas de 1950 a 2010. Assim, constata-se que essas mudanças espaciais e as futuras transformações, podem ser inseridas como parte integrante da história de São Miguel do Oeste e indispensáveis para a conformação do atual tecido urbano. 


\section{Considerações Finais}

A ocupação do espaço urbano na cidade de São Miguel do Oeste seguiu uma lógica relativamente simples, onde é fundamental a existência de água, a disponibilidade de alimento e o menor gasto de energia possível. Nesse sentido, o fato de uma cidade iniciar próxima a um curso d’água potável, com relevo plano e solo fértil é bem lógico. Entretanto, tais situações tornam-se complexas quando os processos imigratórios se intensificam e a busca por melhores condições de vida e progresso ganham importância.

O homem tende a se adaptar ao meio e, nesse contexto, o ambiente que era considerado inóspito, torna-se um potencial à medida que a técnica e a transferência de informação passam a existir. Além de suas famílias, o imigrante trouxe consigo informação e força de trabalho, e o ambiente ofereceu condição de vida favorável e matéria-prima. Esses fatores reunidos fazem surgir às cidades, com sua complexidade e beleza.

São Miguel do Oeste, assim como a maioria dos municípios brasileiros, enfrentou situações de ocupações desordenadas derivadas do êxodo rural, cujo contingente migratório ocasiona a multiplicação populacional e territorial. Posterior a esse fenômeno, tem-se a estagnação do deslocamento do campo para a cidade, e o surgimento de novas legislações amparando os direitos ambientais e reduzindo a implantação de loteamentos irregulares. Contudo, a expressiva densidade habitacional de São Miguel do Oeste, demonstra o potencial histórico que forma seu patrimônio, e deixa como reflexão a possibilidade de minimização dos problemas citadinos, pela formação de uma gestão estratégica do espaço geográfico em questão, capaz de garantir a qualidade de vida populacional.

Ademais, destaca-se que apesar das limitações encontradas quanto à identificação de acervos documentais do município de São Miguel do Oeste referentes à sua expansão urbana, o objetivo do presente artigo foi alcançado. No entanto, tem-se como perspectiva para trabalhos futuros, a análise do contexto social da expansão urbana deste município, relacionando-o com os aspectos topológicos e geomorfológicos.

\section{Referências}

Bonette, L. R., \& Reis, J. G. M. dos (2021). Composição, concentração e classificação do transporte urbano de massa inteligente e sustentável em quatro cidades inteligentes. Revista do Research, Society and Development, 10, 1-10. https://rsdjournal.org/index.php/rsd/article/view/20634.

De Biasi, M. (2011). A carta clinográfica: os métodos de representação e sua confecção. Revista do Departamento de Geografia, 6, 45-60. http://www.revistas.usp.br/rdg/article/view/47110.

Fontolan, B. L. \& Iarozinski Neto, A (2021). Sustentabilidade na habitação de interesse social: análise bibliométrica. Revista do Research, Society and Development, 10, 1-10. https://rsdjournal.org/index.php/rsd/article/view/21338.

Garcia, D. G. (2013). Desafios da expansão urbana em áreas ambientalmente frágeis - o entorno da Rodovia Darly Santos - Vila Velha - E.S. Dissertação de Mestrado em Arquitetura e Urbanismo, Universidade Federal do Espírito Santo. Vitória, Brasil.

Instituto Brasileiro de Geografia e Estatística (2007). Cadastro central de Empresas 2006. https://cidades.ibge.gov.br/brasil/sc/sao-miguel-dooeste/pesquisa/19/29765?ano=2006\&indicador=29764\& tipo=grafico.

Instituto Brasileiro de Geografia e Estatística (2016). Censo Demográfico. https://sidra.ibge.gov.br/Tabela/202.

Instituto Brasileiro de Geografia e Estatística (2018). Dados do Município de São Miguel do Oeste. https://cidades.ibge.gov.br/brasil/sc/sao-miguel-dooeste/panorama.

Instituto Brasileiro de Geografia e Estatística (1955). Estado de Santa Catarina: Censo Demográfico. VI Recenseamento geral do Brasil - 1950. Rio de Janeiro, v. XXVII.

Modenesi-Gauttieri, M. C. \& Hiruma, S. T. (2004). A expansão urbana no planalto de Campos do Jordão: diagnóstico geomorfológico para fins de planejamento. Revista do Instituto Geológico, 25, 1-28. http://ppegeo.igc.usp.br/index.php/rig/article/view/8900/8166.

Pires, C. L. Z. (2008). A complexidade do ambiente urbano e seu reflexo na geografia do Bairro Restinga de Porto Alegre (RS). In N. Dorval do \& B. João Batista (Orgs.). Dimensões do urbano: múltiplas facetas da cidade. Chapecó: Argos.

Riffel, E. S. (2012). Análise e mapeamento das ocorrências de movimentos de massa na bacia hidrográfica do rio Paranhana (RS). Dissertação de Mestrado em Geografia, Universidade Federal do Rio Grande do Sul. Porto Alegre, Brasil. 
Research, Society and Development, v. 10, n. 14, e300101421870, 2021

(CC BY 4.0) | ISSN 2525-3409 | DOI: http://dx.doi.org/10.33448/rsd-v10i14.21870

Rodrigues, A. M. (2008). O espaço urbano e as estratégias de planejamento e produção da cidade. In P. E. Manoel (Org.). Planejamento urbano no Brasil: conceitos, diálogos e práticas (Parte II, 101-126). Chapecó: Argos.

Saadi, A. (1997). A geomorfologia como ciência de apoio ao planejamento urbano em Minas Gerais. Revista Geonomos, 5, 1-4. https://periodicos.ufmg.br/index.php/revistageonomos/article/view/11480.

São Miguel Do Oeste. (2009). Diagnóstico do Plano Diretor Municipal. São Miguel do Oeste.

Serviço Brasileiro de Apoio às Micro e Pequenas Empresas (2010). Santa Catarina em números - São Miguel do Oeste. http://www.sebraesc.com.br/scemnumero/arquivo/Sao-Miguel-do-Oeste.pdf.

Silva, F. B. e, Marques, T. S. \& Delgado, C. (2012). Processos de expansão urbana e mudanças na paisagem: ensaio metodológico (1950-2000). Revista da Faculdade de Letras-Geografia, 1, 161-183. http://ojs.letras.up.pt/index.php/geografia/article/view/16/16.

Souza, M. L. de. (2015). Mudar a cidade: uma introdução crítica ao planejamento e à gestão urbanos (10a ed.). Bertrand Brasil.

Spenassatto, L. A. P. (2008). A história da imigração em São Miguel do Oeste para o desenvolvimento regional. Gráfica \& Editora Ryus Ltda.

Sugai, M. I. (2015). Segregação silenciosa: investimentos públicos e dinâmica socioespacial na área conurbada de Florianópolis (1970-2000). Editora da UFSC.

Wollf, J. N. (2008). Escritos sobre a cidade: “As mil portas” da modernização de Chapecó (1960/1970). In N. Dorval do \& B. João Batista (Orgs.). Dimensões do urbano: múltiplas facetas da cidade. Argos. 